\title{
Multiletramentos: o potencial didático-pedagógico nas relações interdiscursivas ${ }^{1}$
}

\author{
Pamela Tais Clein Capelin ${ }^{\mathrm{i}}$ \\ Gabriel Fischer Lottermann ${ }^{\text {ii }}$ \\ Greice da Silva Castela ${ }^{\text {iii }}$
}

\section{RESUMO}

Objetiva-se realizar, a partir da temática do êxodo, uma leitura interdiscursiva, considerando diferentes textos-enunciados, a fim de desenvolver uma análise do potencial pedagógico para o ensino de Língua Portuguesa na Educação Básica. Para as análises e discussões, embasa-se teórico-metodologicamente na Análise Dialógica do Discurso - ADD (BAKHTIN, 1992 [1929]; 2003 [1979]); (FIORIN, 2006) e nos Multiletramentos (ROJO, 2013; 2017), além dos documentos parametrizadores da educação, como a Base Nacional Comum Curricular - BNCC (2018) e o Referencial Curricular do Paraná - RCPR (2018). Como resultados, destaca-se o potencial dos textos-enunciados multiculturais e multimodais como instrumentos formativos, que possibilitam aprimorar o cabedal teórico e prático nos processos de multiletramentos.

Palavras-chave: Multiletramentos; Relações interdiscursivas; Língua Portuguesa.

\begin{abstract}
The aim is to perform an interdiscursive reading from the theme of exodus, considering different texts-utterances, in order to develop an analysis of the pedagogical potential for teaching Portuguese Language in Primary Education. For the analysis and discussions, this work is theoretically and methodologically based on the Dialogic Discourse Analysis - ADD (BAKHTIN, 1992 [1929]; 2003 [1979]); (FIORIN, 2006) and in Multiliteracies (ROJO, 2013; 2017), besides the parameterizing documents of education such as the Common National Curriculum Basis - BNCC (2018) and the Curriculum Reference of Paraná - RCPR (2018). As a result, one can highlight the potential of multicultural and multimodal texts-utterances as training tools, which make
\end{abstract}

\footnotetext{
i Mestranda em Letras Linguística (UNIOESTE). Especialista em Alfabetização e Letramento; Tecnologias da Informação e Comunicação na Educação; Literatura Brasileira (UNINA). Graduada em Letras Português e Espanhol (UFFS). https://orcid.org/0000-0003-4348-4191. E-mail: pamelaclein88@gmail.com
}

\footnotetext{
ii Mestrando em Letras pela Universidade Estadual do Oeste do Paraná - Unioeste, Campus Cascavel/PR, bolsa CAPES. E-mail: gabriel.lottermann@unioeste.br

iii Pós-Doutora em Letras pela Universidade do Estado do Rio de Janeiro (UERJ). Doutora em Letras Neolatinas pela Universidade Federal do Rio de Janeiro (UFRJ). Professora dos Programas de Pósgraduação Stricto Senso em Letras (PROFLETRAS e PPGL) da Universidade Estadual do Oeste do Paraná (UNIOESTE). E-mail: greicecastela@yahoo.com.br
} 
it possible to improve the theoretical and practical research sources in multiliteracies processes.

Keywords: Multiliteracies; Interdiscursive relations; Portuguese language.

\section{INTRODUÇÃO}

O trabalho voltado aos multiletramentos exige a (re)adaptação contínua da escola no que tange às abordagens didático-pedagógicas na formação dos sujeitos para atuação nos espaços sociais/tecnológicos, visto que "se os textos da contemporaneidade mudaram, as competências/capacidades de leitura e produção de textos exigidas para participar de práticas de letramento atuais não podem ser as mesmas" (ROJO, 2009, p. 8). Com base no exposto, favorecer a inserção adequada dos sujeitos em âmbito social demanda, dentre outras coisas, possibilitar espaços propícios para o contato com as variadas linguagens, de modo que o ensino de Língua Portuguesa colabore para a formação cidadã e identitária dos estudantes.

Este artigo reflete sobre o potencial didático-pedagógico de uma fotografia, de autoria de Sebastião Salgado, em relações interdiscursivas ${ }^{2}$ com outros textosenunciados que favorecem os multiletramentos na Educação Básica. Segundo a BNCC (2018) é preciso favorecer "o uso de diferentes procedimentos e gêneros de apoio à compreensão, tendo em vista os objetivos em questão e as características do texto dado à leitura/estudo, articulando com atividades das outras áreas do conhecimento e com projetos pessoais" (BRASIL, 2018, p. 507).

Em vista do exposto, objetiva-se analisar os pressupostos teóricos acerca dos multiletramentos, com o intuito de compreender em que medida textos-enunciados que tratam das culturas à margem contribuem, em caráter interdiscursivo, para uma formação multicultural e multimodal, a fim de desenvolver uma análise do potencial pedagógico dessas obras para o ensino de Língua Portuguesa na Educação Básica.

A abordagem teórica é fundamentada na Análise Dialógica do Discurso, doravante ADD, (BAKHTIN, 1992 [1929]; 2003 [1979]); (FIORIN, 2006) e nos Multiletramentos (ROJO, 2013; 2017), além dos documentos parametrizadores da 
Educação como a Base Nacional Comum Curricular (2018), a partir de agora BNCC, e o Referencial Curricular do Paraná (2018), daqui em diante RCPR. A investigação caracteriza-se como teórica, com abordagem qualitativa dos dados bibliográficos e documentais, com fins explicativos (LAKATOS; MARCONI, 2003).

Para a clareza e explanação sobre a pesquisa, o artigo organiza-se em duas seções: a primeira trata do aporte teórico que norteia o estudo e a segunda, por sua vez, discorre sobre a compreensão acerca das relações interdiscursivas presentes em uma fotografia de Sebastião Salgado, analisando o potencial didático-pedagógico desses textos-enunciados no viés dos multiletramentos para o ensino de Língua Portuguesa na Educação Básica.

\section{OS MULTILETRAMENTOS PARA AS PRÁtiCAS SOCIAIS NO USO DA LÍNGUA(GEM)}

O termo "pedagogia dos multiletramentos" surge a partir de discussões do Grupo de Nova Londres - New London Group, ${ }^{3}$ em 1994. As práticas multiletradas abarcam o uso das novas linguagens, como, por exemplo, as digitais, que "condi[zem] com os princípios de pluralidade cultural e de diversidade de linguagens envolvidas no conceito de multiletramentos" (ROJO, MOURA, 2012, p. 300). Nesse sentido, os multiletramentos na esfera escolar demandam o "uso integrado de diferentes recursos comunicativos, tais como linguagem [texto verbal], imagem, sons e música em textos multimodais e eventos comunicativos" (VAN LEEUWEN, 2011, p. 668). Nesse viés, Rojo e Moura ressaltam que:

\footnotetext{
O conceito de multiletramentos aponta para dois tipos específicos e importantes de multiplicidade presentes em nossas sociedades, principalmente as urbanas, na contemporaneidade: a multiplicidade cultural das populações e a multiplicidade semiótica de constituições dos textos por meio dos quais ela se informa e se comunica (ROJO; MOURA, 2012, p. 13).
}

Nesse sentido, promover, na escola, práticas voltadas para os multiletramentos envolve refletir acerca das abordagens de um determinado conteúdo a ser mediado, do planejamento, dos materiais de apoio, da formação docente, entre outros fatores que impactam diretamente no processo educativo, uma vez que "devido ao ritmo implacável 
da evolução das tecnologias de comunicação e informação, texto e imagens estão cada vez mais juntos criando textos multimodais"4 (MARTINEC, SALWAY, 2005, p. 337; tradução nossa). Para Rojo:

Podemos dizer que, por efeito da globalização, o mundo mudou muito nas duas últimas décadas. Em termos de exigências de novos letramentos, é especialmente importante destacar as mudanças relativas aos meios de comunicação e à circulação da informação (ROJO, 2009, p. 105).

Utilizar as novas tecnologias nas práticas sociais de uso da língua(gem) pressupõe letramentos em que "é preciso dominar bem os gêneros para empregá-los livremente" (BAKHTIN, 2003 [1979], p. 284), ou seja, o aluno, que muitas vezes desconhece os gêneros discursivos, ou não sabe como utilizá-los de modo apropriado, tem comprometida "a participação em determinada prática social [que] é possível quando o indivíduo sabe como agir discursivamente numa situação comunicativa, ou seja, quando sabe qual gênero do discurso usar” (KLEIMAN, 2007, p. 12). Em vista do exposto, cabe à escola, enquanto espaço de formação, favorecer os subsídios necessários para que os sujeitos utilizem os gêneros multissemióticos nas práticas de leitura, escrita e análise linguística, em prol da ampliação dos conhecimentos sócio-histórico-culturais. Para Castela e Meotti:

[...] os recursos semióticos possibilitam uma ampliação no processo de comunicação pois cada situação comunicativa abre ao sujeito, através de aplicativos e programas disponíveis pelas tecnologias, possibilidades de hibridizar os textos e, consequentemente, produzir novos significados, de acordo com o propósito comunicativo (CASTELA; MEOTTI, 2017, p. 786).

As práticas de multiletramentos exigem o planejamento e a execução de ações em um viés que precisa considerar a realidade histórica, social, cultural e ainda situada em um espaço-temporal determinado para que faça sentido aos estudantes, logo é preciso "[c]onsiderar a diversidade de gêneros escritos, orais e multissemióticos [...] nas práticas de leitura, escuta e produção propostas" (BRASIL, 2018, p. 507). A formação do alunado para as práticas sociais requer o posicionamento crítico e reflexivo acerca de conhecimentos que abrangem os usos da lingua(gem) e suas tecnologias. Para Bakhtin e Volochinov: 
[...] toda palavra comporta duas faces. Ela é determinada tanto pelo fato de que procede de alguém, como pelo fato de que se dirige para alguém [...]. Se ela se apoia sobre mim numa extremidade, na outra apoia-se sobre o meu interlocutor. A palavra é o território comum do locutor e do interlocutor (BAKHTIN, 1992 [1929], p. 113).

Se por um lado o professor atua enquanto mediador de conhecimentos na ampliação de experiências educativas, para além das que o aluno traz consigo de sua vivência enquanto sujeito sócio-histórico-ideológico, por outro lado espera-se que o aluno corresponda ativa e responsivamente 5 na assimilação de "novos" conhecimentos, certos de que "toda compreensão é prenhe de resposta" (BAKHTIN, 2003 [1979], p. 271), para a construção de saberes coletivos, na formação no viés dos multiletramentos.

Letrar para os usos dos gêneros multimodais em situações reais de comunicação presume "os usos e práticas de linguagens (múltiplas semioses), para produzir, compreender e responder a efeitos de sentido, em diferentes contextos e mídias" (ROJO, 2009, p. 119). Nesse sentido, o estudante utiliza a linguagem como instrumento dialógico, como ferramenta através da qual se expressará enquanto sujeito social, mediará conhecimento e atuará sobre o outro e sobre o contexto que o cerca, relacionando a face formal da língua, isto é, o sistema linguístico, e a face discursiva do sistema translinguístico, ${ }^{6}$ de caráter social e histórico.

Toma-se, então, o texto-enunciado inserido nas práticas sociais como o centro norteador do processo de ensino de Língua Portuguesa, tornando-o objeto de análise, o que coaduna com "[d]iversificar gêneros, suportes e mídias definidos para a socialização dos estudos e pesquisas" (BRASIL, 2018, p. 507). Com efeito, o estudo dos processos de enunciação promove, nos sujeitos envolvidos, professor e aluno, a apropriação dos multiletramentos necessários para os usos da língua(gem) nas práticas linguísticas contemporâneas. Ora, uma vez que se utiliza diferentes formas de linguagem em diferentes contextos, é necessário para a escola promover ações que contribuam para os letramentos dos estudantes, capacitando-os para que atuem sobre seus interlocutores nessas práticas sociais.

Os sujeitos comunicam-se, cada vez mais, por meio de textos-enunciados verbais, verbo-visuais e não verbais, recorrentemente, inclusive, com aqueles que circulam na esfera digital. Os textos multimodais são, por sua vez, compostos de uma multiplicidade de semioses, linguagens, mídias e tecnologias. Nesse sentido, há a necessidade formativa, no viés dos multiletramentos, para as práticas de leitura e de 
produção desses gêneros, uma vez que é preciso saber selecionar, avaliar informações, compreender determinadas funções, usos e ferramentas (áudio, vídeo, imagem, entre outros), para a comunicação via gêneros digitais. Requer-se, portanto, dos sujeitos, o domínio de um conjunto amplo de conhecimentos acerca das novas práticas multiletradas na integração de semioses (ROJO, 2013).

Em vista do exposto, compreende-se que a escola exerce o papel fundamental para o desenvolvimento das práticas no viés dos multiletramentos. Nesse sentido, as proposições didático-pedagógicas precisam ser condizentes "com os princípios de pluralidade cultural e de diversidade de linguagens envolvidas no conceito de multiletramentos" (ROJO; MOURA, 2012, p. 300). Para tal, exige-se também a formação adequada aos professores e o planejamento minucioso de cada uma das etapas que compõem as ações formativas, o que condiz com "[o]rganizar situações de estudo e utilizar procedimentos e estratégias de leitura adequados aos objetivos e à natureza do conhecimento em questão" (BRASIL, 2018, p. 508). O viés do desenvolvimento de diversas habilidades de uso da língua(gem) é necessário para a inserção dos sujeitos nas esferas sociais, cada dia mais digitais. Rojo, em referência aos multiletramentos, destaca que:

\footnotetext{
(a) eles são interativos; mais que isso, colaborativos;

(b) eles fraturam e transgridem as relações de poder estabelecidas, em especial as relações de propriedade (das máquinas, das ferramentas, das ideias, dos textos [verbais ou não]);

(c) eles são híbridos, fronteiriços, mestiços (de linguagens, modos mídias e culturas) (ROJO, 2013, p. 23).
}

Nesse sentido, faz-se necessário um ensino que possibilite aos alunos atuarem com os seus interlocutores por meio dos mais diferentes gêneros discursivos, compreendendo as multissemioses e as múltiplas culturas. Na escola, a depender da situação comunicativa, opta-se pelo trabalho com um gênero ou com outro, pois "é pela análise do contexto que se determina o gênero a ser trabalhado, as capacidades de linguagem que os alunos já dominam e aquelas que precisam ser aprendidas" (CRISTOVÃO, 2005, p. 158). Assim como os gêneros impressos, ${ }^{7}$ os gêneros digitais também variam no que tange ao estilo, ${ }^{8}$ ao conteúdo temático ${ }^{9}$ e à construção composicional $^{10}$ (BAKHTIN, 1992 [1929]), logo o “o emprego da língua se efetua em forma de enunciados (orais, escritos e verbo-visuais) concretos e únicos, proferidos 
pelos integrantes desse ou daquele campo da atividade humana" (BAKHTIN, 2003 [1979], p. 261). Para Rojo:

[...] as práticas de trato com os textos multimodais ou multissemióticos contemporâneos - majoritariamente digitais, mas também impressos -, que incluem procedimentos (como gestos para ler, por exemplo) e capacidades de leitura e produção que vão muito além da compreensão e produção de textos escritos, pois incorporam a leitura e (re)produção de imagens e fotos, diagramas, gráficos e infográficos, vídeos, áudio etc. (ROJO, 2017, p. 4).

Por um lado, exemplo dos gêneros impressos são as fotografias, poemas, conto, fábula, crônica, romance, lenda, entre outros. Por outro lado, os gêneros multissemióticos que circulam na esfera digital são, por exemplo, as fotografias, os ciberpoemas, infográficos, podcast, vlog, wiki, fanfiction (BRASIL, 2018; PARANÁ, 2018), entre outros, compostos pela diversidade de semioses, áudio, movimento, vídeo, imagem, diagramação, entre outras. Nesse sentido, "ensinar o aluno a interagir por meio da língua é ensinar o aluno a produzir textos, orais e escritos, que atendam à necessidade de interlocução proposta naquela situação de uso da linguagem" (COSTAHÜBES, 2009, p. 138).

Em vista da breve explanação acerca dos gêneros impressos e digitais, salientase que o gênero discursivo fotografia, é, portanto, não só um gênero impresso, mas também digital, que evoluiu ao longo das décadas e que se configura enquanto importante recurso didático-pedagógico para o ensino de línguas, em vista do potencial de uso de uma linguagem que favorece a compreensão dos interlocutores a respeito das identidades dos sujeitos fotografados. O uso dessa ferramenta é significativo na perspectiva das intervenções em sala de aula pela necessidade de que a educação visual seja popularizada nos espaços sociais. A leitura ativa e responsiva de uma fotografia engloba, nesse sentido, a capacidade minuciosa de observação e análise crítica em vista do contexto de produção e de recepção do texto "além da imagem tornar viva uma mensagem, de lhe dar cor e feição, aciona nossa afetividade e nossa emoção, orientando a atenção do interlocutor" (COSTA, 2005, p. 81-82). Nesse viés, no processo de tratamento dos gêneros discursivos, deve ser objetivo da aprendizagem para o aluno, conforme sugere a BNCC, "[1]er, produzir e analisar textos multimodais estabelecendo relações entre escrita, fala, sons, música, imagens (fotografias, telas, ilustrações, imagens em movimento, grafismos), dentre outras linguagens" (BRASIL, 2018, p. 41). 
Assim, a performance do aluno nas práticas sociais demanda da apropriação e do desenvolvimento constante das competências linguístico-discursivas de gêneros que exploram os aspectos verbo-visuais. A partir do estudo dos diversos gêneros discursivos, promove-se a inserção adequada dos estudantes em suas práticas linguísticas por meio do ensino-aprendizagem dos diversos gêneros com os quais eles têm contato nas esferas sociais das quais fazem parte. Assim, educar na contemporaneidade abarca:

\begin{abstract}
Para além de consolidar habilidades envolvidas na escuta, leitura e produção de textos que circulam no campo, o que se pretende é propiciar experiências que mantenham os jovens interessados pelos fatos que acontecem na sua comunidade, na sua cidade e no mundo e que afetam as vidas das pessoas (BRASIL, 2018, p. 510).
\end{abstract}

Nesse sentido, as fotografias de Sebastião Salgado, por exemplo, contribuem para a formação multimodal e multicultural nas aulas de Língua Portuguesa, em vista de ser uma ferramenta educativa que possibilita aprimorar o uso da linguagem nos processos de multiletramentos, visto "que as imagens também são textos, podem ser lidas e interpretadas, solicitam alguma sistematização e provocam processos semióticos” (RIBEIRO, 2018, p. 71). Para Mauad, a fotografia “[...] contém outros espaços que a determinam e estruturam, como, por exemplo, o espaço geográfico, o espaço dos objetos (interiores, exteriores e pessoais), o espaço da figuração e o espaço das vivências, comportamentos e representações sociais” (MAUAD, 1996, p. 10), isto é, a fotografia atua, portanto, como representação discursiva, carregada de significações.

\title{
RELAÇÕES INTERDISCURSIVAS: A TEMÁTICA DO ÊXODO NO RETRATO DE CULTURAS À MARGEM
}

O gênero discursivo fotografia passou por inúmeras transformações desde os registros de artes rupestres nas cavernas até a fotografia digital, na contemporaneidade, mas mantendo sua principal característica de que "a invenção da fotografia representou a criação de um poderoso instrumento para a exploração visual do espaço e a apreensão do tempo vivido" (TURAZZI, 2005, p. 4). Enfoca-se, neste estudo, acerca de um registro fotográfico de Sebastião Salgado, "um dos fotógrafos brasileiros de maior 
reconhecimento internacional, que desenvolve seus projetos viajando pelo mundo, tendo já passado por mais de cem países" (AUROCA, 2012, p. 27) e registros de guerras, de trabalhadores, retrato de êxodos, entre outros, em que o artista revela a realidade vivenciada por sujeitos em condições de vida precárias, representadas nas fotografias em preto e branco.

O uso da fotografia em sala de aula, como a de Sebastião Salgado, configura-se enquanto importante ferramenta com amplo potencial didático-pedagógico por retratar culturas marginalizadas. Trabalhar com a leitura de aspectos visuais além de instigante, possibilita que experiências significativas sejam refletidas acerca de conteúdos diversos, relacionados a qualquer esfera de atividade humana. Cabe ressaltar que a utilização de imagens enquanto ferramentas de leitura e posicionamento crítico passa muitas vezes despercebida, se configurando, por exemplo, no livro didático, enquanto elemento meramente decorativo de um conteúdo, quando na verdade é uma estratégia profícua que atua na ampliação de conhecimentos de mundo. Desse modo:

As fotos não são meras ilustrações ao texto. As fontes fotográficas são uma possibilidade de investigação e descoberta que promete frutos na medida em que se tenta sistematizar suas informações, estabelecer metodologias adequadas de pesquisa e análise para a decifração de seus conteúdos e, por consequência da realidade que os originou (KOSSOY, 1989, p. 20).

Explorar o potencial didático-pedagógico de fotografias demanda a mediação do professor, que precisa considerar e incluir essa ferramenta nas discussões em sala, junto aos alunos, na construção coletiva de conhecimentos, na compreensão da realidade, por meio de "informação e conhecimento, instrumento de apoio nos diferentes campos da ciência e também como fonte de expressão artística" (KOSSOY, 1989, p. 14). As fotografias são uma forma de registrar gerações, culturas, transformações, logo é uma fonte documental no "registro de alguma coisa, explícita ou implicitamente, o que lhe empresta sempre uma dualidade inseparável - existe o objeto-fotografia e também o conteúdo dessa fotografia que precisam ser levados em conta, conjuntamente ou não" (LEITE, 1983, p. 144).

O trabalho com a fotografia pressupõe a leitura de mundo, uma vez que nela está expressa uma série de escolhas que envolvem o objeto, uma dada situação comunicativa, o cenário, o conjunto de elementos que compõe esse texto-enunciado, o enquadramento da câmera, o tempo determinado e situado, escolhas e estratégias do 
fotógrafo nos registros. As práticas didático-pedagógicas centradas em abordagens a partir de textos multimodais facilitam aos sujeitos "[b]uscar informações sobre algum tema a ser estudado [...] fazendo uso da leitura das fotos ou legendas para se apropriar de informações" (PARANÁ, 2018, p. 167).

Em vista disso, "[a] leitura da mensagem visual depende simultaneamente de uma concepção global e de uma análise de pormenores” (LEITE, 1983, p. 158), e essas informações permitem produzir conhecimentos acerca do que é observado no texto imagético. Soma-se a isso o fato de que "as imagens fotográficas conseguem revelar formas de classificar e aprender, entre outras coisas, as relações sociais e as ideologias dos sujeitos que, de alguma forma, contribuíram para a sua produção" (CAMPOS, 1992, p. 103).

Considera-se, nesse artigo, que a abordagem educativa por meio da fotografia de Sebastião Salgado, sob a mediação docente, favorece a apropriação de conhecimentos, sobretudo quando se trata da temática das culturas à margem. No processo educativo, é preciso favorecer ao estudante, conforme destacado pelo RCPR, "[p]articipar de situações que envolvam a leitura de textos, onde utiliza-se diferentes suportes" (PARANÁ, 2018, p. 70). Os registros desse fotógrafo atuam enquanto documento histórico que transcende à simples representação imagética, assim:

\footnotetext{
Para ensinar com ajuda de imagens o professor deve ter em mente que a fotografia funciona como um mediador cultural, ou seja, atua na interação entre conhecimentos prévios e novos conhecimentos. Esta interação ocorre de forma dialógica, onde está presente a ideia de múltiplas vozes, o contato com várias linguagens (GEJÃO; MOLINA, 2008, p. 1).
}

As fotografias enquanto ferramentas educativas pressupõem abordagens dialógicas no ensino de línguas, seja com o objetivo de conhecer acerca do artista e fotógrafo Sebastião Salgado, em discutir o contexto social e histórico no registro por meio das fotografias, nas possíveis leituras e contextualizações dessas obras, na construção de novos conhecimentos de modo significativo e motivador, ao impulsionar a imaginação, criatividade e a possibilidade de experienciar o contato com os textosenunciados verbo-visuais, multimodais, conforme nota-se na fotografia abaixo:

\section{Texto-enunciado 1- Fotografia $\hat{E x o d o ~(S A L G A D O, ~ 2000) ~}$}




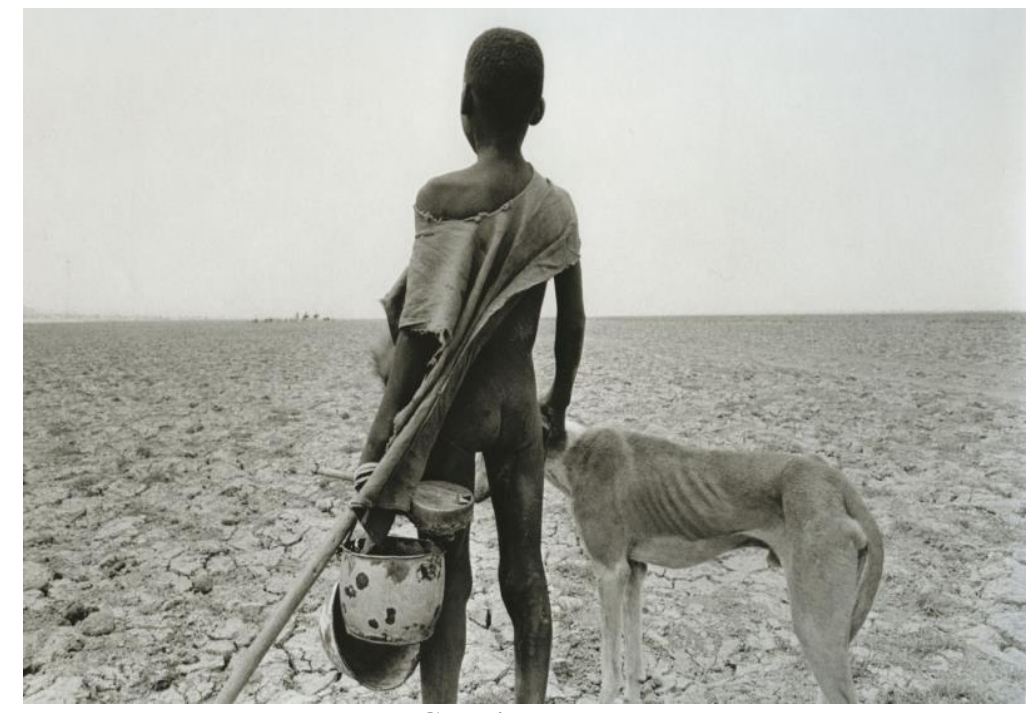

Fonte: Google Imagens

A imagem acima, registrada por Sebastião Salgado, intitulada Exxodo (SALGADO, 2000), está presente no documentário O Sal da Terra, que reuniu os trabalhos desenvolvidos pelo fotógrafo em Serra Pelada, na África e no Nordeste brasileiro. A fotografia apresenta, aparentemente, um menino e um cachorro, de costas, ambos desnutridos, fato evidenciado pela condição física dos dois, que não enxergam nada mais do que uma imensidão de chão seco, rachado pela falta de umidade, da falta de vegetação e de qualquer outro tipo de vida. A cena, em preto e branco, apresenta um ambiente de extrema miséria em que não há nada pela frente, simbolizando para o menino, colocado na posição de protagonista, que em seu futuro não há vida.

$\mathrm{Na}$ perspectiva interdiscursiva, ao explorar na escola, por exemplo, os aspectos da enunciação da fotografia, podem-se estabelecer relações enunciativas com outras obras que trazem a temática do êxodo e das culturas à margem, logo favorece ao educando, de forma contextualizada, "[p]articipar de situações significativas de leitura e escrita" (PARANÁ, 2018, p. 73). A partir dessa perspectiva vislumbram-se abordagens educacionais no viés, segundo Rojo, dos multiletramentos e gêneros que ela incorpora, típicos dos novos letramentos, de um aluno "mais preparado para a vida investigativa e colaborativa do mundo contemporâneo" (ROJO, 2017, p. 6). Para tal, é preciso que o professor perceba e incorpore em suas práticas docentes os gêneros multimodais e multissemióticos, enquanto aliados na formação do aluno na condição de um sujeito crítico, autônomo e protagonista de todo processo de ensino-aprendizagem na esfera 
escolar. Assim, o objetivo da escola deve ser formar um aluno capaz de ressignificar a realidade na qual está inserido.

Conforme visto anteriormente, a multiculturalidade e a multimodalidade de semioses podem ser exploradas na obra de Sebastião Salgado, assim favorece aos estudantes a "leitura da produção artística, que o processo de criação envolve ação investigativa, pesquisa, experimentação, levantamento de hipóteses, reflexão, acaso, sendo, tanto o produto artístico, como também o processo, significativos" (PARANÁ, 2018, p. 233). Nesse sentido, pode-se, também, estabelecer relações da foto com outros textos-enunciados, em caráter interdiscursivo, como, por exemplo, a obra Vidas Secas (1938) de Graciliano Ramos; a pintura Retirantes (1944) de Cândido Portinari; e a música Morte e Vida Severina (1966) de Chico Buarque, entre outros gêneros multissemióticos que tratam acerca da temática que abarca as culturas à margem.

Cabe salientar a existência de uma diferenciação entre intertextualidade e interdiscursividade, destacada por Fiorin:

\begin{abstract}
Se há uma distinção entre discurso e texto, poderíamos dizer que há relações dialógicas entre enunciados e entre textos. Assim, devem-se chamar intertextualidade apenas as relações dialógicas materializadas em textos. Isso pressupõe que toda intertextualidade implica a existência de uma interdiscursividade (relações entre enunciados), mas nem toda interdiscursividade implica uma intertextualidade. Por exemplo, quando um texto não mostra, no seu fio, o discurso do outro, não há intertextualidade, mas há interdiscursividade (FIORIN, 2006, p. 51).
\end{abstract}

Ora, este artigo propõe discutir o caráter interdiscursivo das obras supracitadas, destacando a valorização de algumas culturas à margem em seus processos de enunciação e, nesse sentido, o consequente potencial didático-pedagógico para o desenvolvimento dos multiletramentos na escola, explorando, também, as múltiplas semioses utilizadas. Assim, toma-se, como exemplo, fragmentos de três enunciados, respectivamente: um trecho do Romance Vidas Secas (1938), de Graciliano Ramos; da pintura Retirantes (1944), de Cândido Portinari; e breves versos da canção Morte e Vida Severina (1966), de Chico Buarque.

\title{
Texto-enunciado 2- Fragmento de Vidas Secas (RAMOS, 1938)
}

Na planície avermelhada os juazeiros alargavam duas manchas verdes. Os infelizes tinham caminhado o dia inteiro, estavam cansados e famintos. Ordinariamente andavam pouco, mas como haviam repousado bastante na areia do rio seco, a viagem progredira bem três léguas. Fazia horas que 
procuravam uma sombra. A folhagem dos juazeiros apareceu longe, através dos galhos pelados da catinga rala (RAMOS, 1938, p. 2).

\section{Texto-enunciado 3 - Pintura Retirantes (PORTINARI, 1944)}

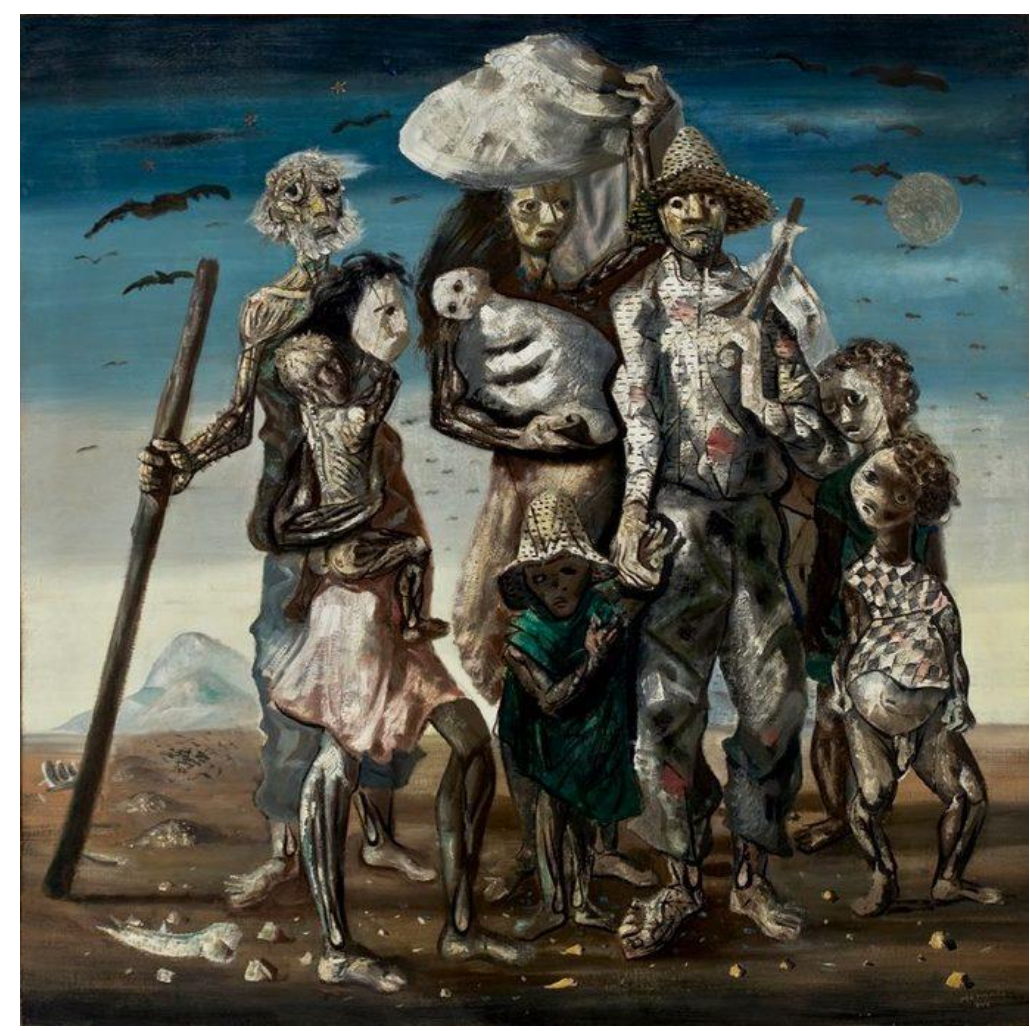

Fonte: Google Imagens.

\section{Texto-enunciado 4 - Versos da canção Morte e Vida}

\section{Severina (BUARQUE, 1966),}

É uma cova grande pra tua carne pouca

Mas à terra dada não se abre a boca

É a conta menor que tiraste em vida

É a parte que te cabe deste latifúndio

(É a terra que querias ver dividida) [...].

Nos três textos-enunciados acima elencados, é observado o retrato, a partir de diferentes linguagens, da miséria brasileira. No texto-enunciado 2, há a construção em prosa de um espaço com chão avermelhado e juazeiros, árvore típica do semiárido brasileiro, compondo um ambiente que na caatinga, com rios secos e pouca folhagem, torna-se de extremas dificuldades para a viagem dos infelizes e famintos personagens. Por sua vez, o texto-enunciado 3, através da construção imagética de Portinari, retrata, aparentemente, uma família de quatro adultos e cinco crianças que, a partir dos traços de 
suas feições e de suas roupas velhas, externalizam o sofrimento em meio a um ambiente de sertão, cercado de pobreza. Por fim, nos versos selecionados da canção Morte e Vida Severina (BUARQUE, 1966), texto-enunciado 4, nota-se um discurso implícito, não verbalizado diretamente, de ironia quanto à questão de que para aquela que tanto trabalhou para o progresso do latifúndio, a terra dada para sua cova era grande demais para sua tão pouca carne, sinalizando a vida em miséria que tivera.

Nesse sentido, percebem-se as relações interdiscursivas estabelecidas entre os textos-enunciados, notando que há nos processos de enunciação, por exemplo, o objetivo de atingir determinados interlocutores, chamando-os à reflexão acerca dos sistemas políticos que sempre estiveram vigentes no Brasil e acabaram, consequentemente, provocando desigualdades. Para além disso, há semelhanças nos papéis sociais dos sujeitos envolvidos, no sentido da não escolha por servir ao poder, permanecendo marginalizados em ambas as situações: como na canção de Chico Buarque, ao assujeitarem-se, ou ao abandonarem a situação e sofrerem pelo descaso dos governantes, perdurando na miséria.

Nesse sentido, o contexto de situação imediato dos três excertos, correspondente às influências no discurso por parte dos interlocutores, é, a princípio, semelhante ao da fotografia de Sebastião Salgado, uma vez que os sujeitos a quem os textos-enunciados são endereçados assumem, provavelmente, posições similares na interação dialógica com a obra, a pintura, a música e a fotografia. Isto é, imagina-se, neste texto-enunciado, que os interlocutores dessas obras possuem formações discursivas que os levarão, em escala de semelhança, a chocarem-se com as situações retratadas. Conforme destacado no RCPR, é preciso "[n]a abordagem de leitura discursiva, a constituição dos sentidos e significados dos textos deve ir além das suas marcas linguísticas, objetivando o desenvolvimento de uma prática analítica e crítica" (PARANÁ, 2018, p. 493-494)

$\mathrm{Na}$ questão do contexto de situação mediato, por sua vez, referente às interferências no discurso pelas condições de produção e o lugar de interação, não parece haver dúvidas que os quatro textos-enunciados retratam realidades análogas. Por último, o contexto do horizonte sócio-histórico, relacionado às ações impostas pelo tempo e lugar histórico, pelos hábitos e pela cultura, pelos estratos sociais e pela ideologia, pelos processos comportamentais, morais, éticos, entre outros, são símeis, uma vez que os processos que levam os sujeitos às situações retratadas são semelhantes, 
ao passo em que as estruturas sociais, impostas pelos grandes poderes, são excludentes e sentenciam grande parte dos sujeitos à miséria.

Nesse sentido, as relações interdiscursivas presentes nos quatro textosenunciados, a fotografia, a canção, a pintura e o fragmento do romance, assumem grande potencial didático, sobretudo quando explorados pelo viés dos multiletramentos, visto que "expande-se o letramento, por meio da gradativa incorporação de estratégias de leitura de textos de nível de complexidade crescente, bem como ampliam-se as estratégias de produção de textos de diferentes gêneros discursivos" (PARANÁ, 2018, p. 532). Ao considerar as múltiplas semioses, isto é, as múltiplas linguagens que compõem esses textos-enunciados, retratam-se as culturas à margem de diferentes modos, ressignificando a realidade social para os sujeitos envolvidos no processo de ensino e, consequentemente, letrando-os para as práticas sociais de uso da lingua(gem).

\section{CONSIDERAÇÕES FINAIS}

Neste artigo, objetivou-se analisar os processos que direcionam aos multiletramentos, compreendendo a potencialidade didático-pedagógica de uma das fotografias de Sebastião Salgado como ferramenta possível para um ensino, de fato, multicultural e multimodal. Nesse sentido, exemplificou-se, para fins de comparação, diferentes obras, enunciadas a partir de distintos gêneros discursivos e que provaram estabelecer relações interdiscursivas em diferentes linguagens. Desse modo, evidenciouse, ao longo deste artigo, o potencial das multissemioses como instrumentos formativos.

Acredita-se, de acordo com as análises desenvolvidas nesta investigação, que a esfera escolar demanda de trabalhos com textos-enunciados que circulam nas esferas sociais contemporâneas, incluindo, nas práticas pedagógicas, gêneros multimodais para além dos tradicionais, de circulação massiva neste século, de modo a favorecer as práticas de leitura, escrita e análise linguística de gêneros presentes nas práticas sociais de uso da língua(gem).

\section{Referências}

AUROCA, C. Arte na escola: como estimular um olhar curioso e investigativo nos alunos dos anos finais do Ensino Fundamental. São Paulo: Anzol Ltda. 2012, 120p. 
BRASIL. Ministério da Educação. Base Nacional Comum Curricular. Brasília, DF: MEC, 2018.

BAKHTIN, M (V. N. Volochinov). Marxismo e filosofia da linguagem. Tradução de Michel Lauch e Iara Frateschi Vieira. 6.ed. São Paulo: Editora Huritec 1992[1929].

BAKHTIN, M. A estética da criação verbal. 4. ed. São Paulo: Martins Fontes, 2003[1979].

BUARQUE, C. 1966. Morte e Vida Severina. Música: You tube. Disponível em: https://www.youtube.com/watch?v=uL9cDmQxMwo . Acesso em: 10 ago. 2021.

CAMPOS, M. C. S. de S. "A associação da fotografia aos relatos orais na reconstrução histórico-sociológica da memória familiar”. In: LANG, A. B da S. G. (org). Reflexões sobre a pesquisa sociológica. São Paulo: CERU, 1992.

CASTELA, G da S; MEOTTI, M.B. "Tecnologia no ensino de Língua Espanhola e Português: algumas possibilidades de uso de ODEAs". $7^{\circ}$ Simpósio de Hipertexto e Tecnologias na Educação - $3^{\circ}$ Colóquio Internacional de Educação com Tecnologias. Universidade Federal de Pernambuco NEHTE /Programa de Pós Graduação em Letras, 2017. Disponível em: http://www.nehte.com.br/simposio/anais/Anais-Hipertexto2017/ANAIS\%20HIPERTEXTO\%202017\%20Greice\%20da\%20Silva\%20CASTELA.p df. Acesso em: 07 ago. 2021.

COSTA, C. Educação, Imagem e Mídias. 1. ed. São Paulo: Cortez. (Aprender e Ensinar com Textos; v.12). 2005. 198 p.

COSTA-HÜBES, T. C. "Reflexões Linguísticas sobre Metodologia e Prática de Ensino de Língua Portuguesa". Liceu Literário: Português, 2009. p.129.

CRISTOVÃO, V. L. L. "Aprendendo a planificar o próprio trabalho: gêneros textuais na formação de professores de língua estrangeira". In: Gêneros textuais: teoria e prática II. Palmas: Kaygangue, 2005. p. 153-162.

FIORIN, J. L. "Interdiscursividade e intertextualidade". In: BRAIT, B. (Org.). Bakhtin: outros conceitos-chave. São Paulo: Contexto, 2006.

GEJÃO, N. G; MOLINA, A. H. "Fotografia e ensino de História: mediadores culturais na construção do conhecimento histórico". Anais do VII seminário de Pesquisa em Ciências Humanas. 17 a 19 de setembro. Londrina: Eduel, 2008.

KOSSOY, B. Fotografia e história. São Paulo: Ática, 1989.

KLEIMAN, A. Letramento e suas implicações para o ensino de língua materna. Signo, Santa Cruz do Sul, v. 32, n. 53, p. 1-25, dez. 2007.

LAKATOS, E. M; MARCONI, M de A. Fundamentos de Metodologia Científica. 5. ed. 
São Paulo: Atlas, 2003.

LEITE, M. M. Retratos de família. São Paulo: Edusp, 1983.

MARTINEC, R.; SALWAY, A. "A system for image-text relation in new (and old) media”. Visual Communication, New York, v. 4, n. 3, p. 337-71, 2005.

MAUAD, A. M. Através da Imagem: Fotografia e História - Interfaces. Tempo. Rio de Janeiro, Vol. 1, n² 1996.

NEW LONDON GROUP. A Pedagogy of Multiliteracies: Designing Social Futures', Harvard Educational Review, v. 66, n. 1, p. 60-92, Spring 1996.

OLIVEIRA, M. B. F de; SZUNDY, P. T. C. Práticas de multiletramentos na escola: por uma educação responsiva à contemporaneidade. Bakhtiniana, São Paulo, 9 (2): 184 205, Ago./Dez. 2014.

PARANÁ. 2018. Referencial Curricular do Paraná: Princípios, Direitos e Orientações. Curitiba, PR: SEED. 901p.

PORTINARI, C. Retirantes. 1944. Disponível em: https://cdn.culturagenial.com/imagens/retirantes-masp-cke.jpg. Acesso em: 10 ago. 2021.

RAMOS, G. Vidas Secas. São Paulo: Record, 1938.

RIBEIRO, A. E. Escrever, hoje: palavra, imagem e tecnologias digitais na educação. São Paulo: Parábola, 2018.

ROJO, R. Letramentos múltiplos, escola e inclusão social. São Paulo: Parábola Editorial, 2009.

ROJO, R.; MOURA, E. (Org.). Multiletramentos na escola. São Paulo: Parábola editorial, 2012.

ROJO, R. Escola conectada: os multiletramentos e as TICs. São Paulo: Parábola, 2013.

ROJO, R. Entre Plataformas, Odas e Protótipos: Novos Multiletramentos Em Tempos De Web2. ESPecialist, ISSN 0102-7077, Vol. 38, №. 1, 2017.

SAlGADO, S. Exxodo. (2000). O Sal da Terra (2015). Imagem: google fotos. Disponível em: https://images.app.goo.gl/YFssMgVUrPHTRT9A6. Acesso em: 11 ago. 2021.

TURAZZI, M. I. Informes e Documento. História, a fotografia e o ensino de história. São Paulo: Editora Moderna, 2005.

VAN LEEUWEN, T. "Multimodality". In: SIMPSON, J. The Routledge handbook of applied linguistics. New York: Routledge, 2011. p. 668-682. 


\footnotetext{
${ }^{1}$ Este trabalho foi desenvolvido na disciplina de Concepções de leitura e letramentos no ensino de línguas em suporte impresso e digital, sob a orientação da professora Dra. Greice da Silva Castela, na Pós-Graduação em Letras, da Universidade Estadual do Oeste do Paraná - Unioeste, Campus de Cascavel/PR, no ano de 2020.
}
${ }^{2}$ Assume-se a noção de interdiscursividade na concepção cunhada pelo círculo de Bakhtin (1992 [1929]). De acordo com Fiorin (2006), trata-se do fato de que na sociedade os discursos são entrelaçados por discursos anteriormente ditos, de outros lugares históricos, e, por isso, relacionam-se, potencialmente, uns aos outros.

3 O New London Group é composto por “dez educadores - Courtney Cazden, Bill Cope, Norman Fairclough, James Gee, Mary Kalantzis, Gunther Kress, Allan Luke, Carmen Luke, Sarah Michaels e Martin Nakata" (OLIVEIRA, SZUNDY, 2014, p. 193).

4 No original, "text and images are increasingly coming together creating multimodal texts" (MARTINEC, SALWAY, 2005, p. 337).

${ }^{5}$ Os termos ativo e responsivo estão amparados nos estudos do Círculo de Bakhtin, uma vez que abarcam o sujeito ativo e responsivo frente às práticas de leitura e de produção de textos dos mais variados gêneros discursivos, pois " $[\mathrm{t}]$ odo enunciado tem sempre um destinatário, cuja compreensão responsiva o autor da obra do discurso procura e antecipa” (BAKHTIN, 2003 [1979], p. 333).

${ }^{6} \mathrm{O}$ sistema translinguístico refere-se, com base em Fiorin (2006), às produções de sentidos com caráter social e histórico de intercâmbio comunicativo, ou seja, ao dialogismo bakhtiniano. Trata-se, portanto, da face discursiva da linguagem, que vai além do sistema linguístico e que está inserida nos processos ideológicos.

7 Toma-se, neste texto, o termo gêneros impressos em referência aos gêneros tradicionais, os quais já circulavam nas comunidades de prática linguística em épocas anteriores ao advento da internet.

${ }^{8}$ Com base no Círculo de Bakhtin, o estilo está expresso na materialidade constitutiva e orgânica de cada gênero discursivo e na proposta individual de cada autor/locutor, pois "a própria escolha de uma determinada forma gramatical pelo falante é um ato estilístico” (BAKHTIN, 2003 [1979], p. 268).

${ }^{9}$ Segundo os postulados bakhtinianos, o conteúdo temático é expresso acerca de um determinado tema, no que o enunciador pretende dizer e na dialogicidade com outros textos (BAKHTIN, 2003 [1979]).

${ }^{10}$ Para o Círculo de Bakhtin, a construção composicional diz respeito à configuração geral do texto, à disposição e à organização das partes (BAKHTIN, 2003 [1979]). 